\title{
Dietary intake of antioxidants and fats in the context of coronary heart disease prevention among elderly people
}

\author{
Emilia Kolarzyk ${ }^{1,2}$, Agata Skop-Lewandowska', Jagoda Jaworska', \\ Agnieszka Ostachowska-Gąsior', Teresa Krzeszowska-Rosiek' \\ 1 Jagiellonian University Medical College Hygiene and Dietetics Dept \\ ${ }^{2}$ Cracow Higher School of Health Promotion
}

Kolarzyk E, Skop-Lewandowska A, Jaworska J, Ostachowska-Gąsior A, Krzeszowska-Rosiek T. Dietary intake of antioxidants and fats in the context of coronary heart disease prevention among elderly people. Ann Agric Environ Med. 2018; 25(1): 131-136. doi: 10.5604/12321966.1233574

\begin{abstract}
Introduction. Some literature data indicate that the proper intake of exogenic antioxidants from food and the proper intake of fats can offer significant protection against coronary heart disease.

Objectives. The estimation of total antioxidant capacity of food intake on the basis of Dietary Antioxidant Index (DAl), together with an assessment of the contribution of particular food products in DAI, and the evaluation of consumption of all dietary fats and frequency of consumption of products that are a source of fats among elderly people in Krakow, Poland.

Materials and method. 143 persons ( 73 women and 70 men) aged 65-80 were studied. None of them was under specialist medical control, including cardiological control. DAI was investigated on the basis of the Food Frequency Questionnaire (FFQ) which included 145 food items. DAl was measured using the method by Benzi and expressed as FRAP (the ability to reduce $\mathrm{Fe}^{3+}$ to $\mathrm{Fe}^{2+}$, measured in $\mathrm{mMol} / \mathrm{l}$ ). The daily intake of fats was estimated using the 24-h nutritional recall. The frequency of fats consumption was estimated with the usage of FFQ. For statistical analysis, $\chi 2$ test was used.

Results The mean value of DAl of all studied persons was $34.27+11.72 \mathrm{mMol} / \mathrm{l}$. The largest percentage of those studied had FRAP values in the range $25-35 \mathrm{mMol} / \mathrm{I}$. The highest contribution in the total DAl value was found in fruit (36.2\%), grains and cereal-based products (23.6\%), and beverages (24.0\%). The consumption of vegetables was on the fourth position (7.1\%). The contribution of the remaining food products was low. The consumption of total fats (about $70 \mathrm{~g} / 24 \mathrm{~h}$ ) and saturated fatty acids ( $14 \%$ of energetic value) exceeded the recommendations. The participation of mono-and polyunsaturated fatty acids in the diets was not in accordance with recommendations. The most frequently consumed fats were animal fats (sausages, butter) and cakes, but the consumption of vegetable oils, fish, nuts and seeds of oil plants was too low.

Conclusions. The majority of elderly people made mistakes in their nutrition. The enrichment in natural antioxidants of the diets of elderly people and the normalization of their fats consumption should become an important element of primary and secondary prophylaxis of cardiovascular diseases.
\end{abstract}

Key words

elderly, Dietary Antioxidant Index, FRAP, dietary fats, monounsaturated fatty acids, polyunsaturated fatty acid, saturated fatty acid, coronary heart disease

\section{INTRODUCTION}

Coronary heart disease (CHD) remains the leading cause of mortality in developed countries and is rapidly becoming a dominant cause of all deaths worldwide $[1,2]$. Multi-centre All-Polish Examinations of the WOBASZ II (14,769 persons aged 20-74; average period of observation -8.2 year) and WOBASZ Senior (1,096 persons aged above 74 ; average period of observation - about 5 years) showed that the mortality associated with $\mathrm{CHD}$ was the most frequent cause of all deaths (within 1,436 of all persons who died; cardiological reasons were stated in 568 persons: $38 \%$ among men and $31 \%$ among women) [2]. The most important modifiable risk factor for cardiovascular disease is diet $[1,3]$, as confirmed in the WOBASZ [4] and INTERHEART studies [5]. Within the WOBASZ study, dietary habits were assessed in 5,690 subjects (2,554 men and 3,136 women). A significant percentage of Poles had improper dietary habits and their diet was not well

Address for correspondence: Emilia Kolarzyk, Jagiellonian University Medical College, Hygiene and Dietetics Dept

E-mail: mykolarz@cyf-kr.edu.pl

Receivd: 22 July 2016; accepted: 7 December 2016; first published on February 2017 balanced. The intake of fats, saturated and polyunsaturated fatty acids, dietary cholesterol and fibre was incompatible with recommended doses among the majority of adult Polish citizens. A half of the studied people consumed an insufficient amount of fruits and vegetables. Moreover, the consumption of vitamins (A, C, E, B1, B2, B6, B12, and especially folate) and mineral elements important in prevention of hypertension (magnesium, calcium and potassium) also was insufficient. The quality of dietary habits of the majority Polish adults falls far short of the recommendations relevant for the prevention of CVD [4].

A standardized case-control study of acute myocardial infarction in 52 countries (INTERHEART study), representing every inhabited continent (including 15,152 cases and 14,820 controls), established that smoking, hypertension, diabetes, abdominal obesity, psychosocial factors, and especially an abnormal lipid level and low consumption of fruits and vegetables, together with low physical activity, accounted for most of the myocardial infarction risks worldwide in both genders and in all regions, regardless of age [5]. It was shown in another study that the main factors which may prevent the majority of cardiovascular disease in Western populations 
are diets, together with regular physical activity, avoidance of smoking and maintenance of a proper body weight. A diet which includes non-hydrogenated unsaturated fats as the predominant form of dietary fat, whole grains as the main form of carbohydrates, an abundance of fruits and vegetables and adequate omega-3 fatty acids, can offer significant protection against $\mathrm{CHD}$ [1]. A diet rich in antioxidants is recognized as being directly associated with cardiovascular protection [6]. Antioxidants are a broad group of nutritional elements which constitute the first line of defence against damage caused by free radicals. Antioxidant compounds are present in vegetables, fruit, and many natural beverages, like tea; therefore, proper balanced diets are naturally rich in antioxidants [7]. Antioxidants scavenge free radicals, reactive oxygen species (ROS) and reactive nitrogen species from cells, preventing or reducing the damage caused by oxidation of the particular body tissues, including heart tissue [6]. Oxidative stress is responsible for myocardial failure progression on the cellular level [8-12]. It has been proved that mitochondria are an important source of reactive oxygen forms. The negative influence of oxidative stress has a direct and an indirect character, not only through degeneration or activation of cell apoptosis, but free radicals may also influence intracellular reactions through signaling pathways, causing changes in proteins' function. The ROS deregulates the innervationcontraction sequence, causing arrhythmia through the influence on proteins of ion channels. They also take part in myocardium remodeling, caused by activation of mentioned signal tracts, that induce outgrowth, apoptosis, necrosis and fibrosis of that cells. Patients with myocardial failure are predisposed to high risk of dysfunction of endothelium because of ROS cummulation and lack of NO (free radicals react easily with $\mathrm{NO}$ and then modify its concentration). The endothelium dysfunction increases the mortality of cardiological patients. Assessment of the different aspects of endothelial dysfunction in cardiovascular medicine in general and in heart failure (HF) should be connected with a wide spectrum of studies, including not only vasomotor, haemostatic and inflammatory [8-12] aspects, but also the measurement of antioxidant activity [6], because the integrated antioxidant defence system plays the main role in the defence against ROS and oxidative stress. In nutritional epidemiology, the intake of antioxidants from food is usually evaluated by the Dietary Antioxidant Index (DAI) [13].

\section{OBJECTIVES}

The primary aim of the study was to estimate diets antioxidant capacity (measured as DAI values) and assess the hierarchy of contribution of particular food products in DAI. A secondary aim was to examine the consumption of all dietary fats: saturated, mono- saturated and polyunsaturated, and cholesterol, as well as the frequency of consumption of products which are a source of fats in the diet of people over the age of 65 , without confirmed cardiovascular diseases.

\section{MATERIALS AND METHOD}

Participants. The study included 143 persons (73 women and 70 men) aged 65-80 who were independent and without any physical or mental disability, free-living in own flats in
Krakow and its suburbs. The common feature of these persons was daily participation in social and physical exercises (4 hours daily, on average) organized by Senior Clubs and City Cultural Centres. The diseases typical for older age were stated in medical interviews, but none of the participants was under specialist medical control, including cardiological control. The studied people did not suffer from any diseases influencing nutritional status. All studied persons gave a written consent to participle in the study. They provided data through questionnaires. The study protocol was approved by the Bioethical Committee of the Medical College of the Jagiellonian University in Kraków (No. KBET/54/B/2014).

Dietary Antioxidant Index (DAI) assessment. Assessed on the basis of the food frequency questionnaire (FFQ), prepared on the basis of American Dietetic Association recommendations [13]. In the FFQ, 145 food items were classified into 9 groups: fruits and dried fruits, vegetables, herbs and spices, grains and cereal-based products, fish and seafood, mixed dishes; oil and dips, sweets, beverages. It was stated in the questionnaire that every nutritional position represents all forms of a particular food (fresh, frozen, cooked or packed in cans), e.g. 'apples' meant fresh fruit, apple juice, compote and apple pie. The participants reported how often they had eaten each food in the previous month. In order to calculate thre DAI for each participant, previously published databases from the USA and Italy containing the most commonly consumed foods were used. The value of a medium portion ( $100 \mathrm{~g}$ of a product, volume of a glass, the content of a soup spoon, or the amount of product necessary to spread over 2 pieces of bread), was written in the questionnaire for every nutritional product. Medium serving size was shown as a reference. A half of a medium portion was treated as a small portion, whereas one and a half of a medium portion or more was classified as a big portion.

The total antioxidant capacity of food intake was measured using the method by Benzi IF [14]. This method exploits the ability of the sample to reduce ferric ions to ferrous ions (FRAP) which are bound in the coloured complex with trpiridyl-S-triazine. FRAP value (measured in $\mathrm{mMol} / \mathrm{l}$ ) was written in the questionnaire for a medium portion. The small portion obtained a half, and a big portion obtained one and a half of the FRAP value. FRAP values specific for the size of portion were multiplied by the amount of portions, and divided for 30 days. The outcome was treated as the size of FRAP value of daily nutritional ration. The sum of FRAP value/day for all nutritional products was treated as the Dietary Antioxidant Index (DAI).

Dietary fat intake assessment - 24-hour dietary recall. Carried out 3 times for each participant ( 2 working days and one feast day). To secure the best reliability of the nutritional assessment, the 24-hour-dietary recall interviews were conducted face-to-face. During the interview, photos of products included in the 'Album of photos of portions of Products and Meals' by the Institute of Food and Nutrition [15] were presented to respondents. The data gathered from the interviews underwent qualitative and quantitative analysis that included percentage participation of energy coming from total fats, fatty acids with the division to saturated fatty acids (SFA), monounsaturated fatty acids (MUFA), polyunsaturated fatty acids (PUFA) and cholesterol. The calculations were performed using software for 
24-hours nutritional recall analysis - Diet-Pro. The results calculated individually for each person were compared with nutritional norms recommended.by the Institute of Food and Nutrition in Warsaw [16], recommendations of Polish Forum of the Prophylactics of Cardiovascular Diseases [17], Healthy Diet according to Polish Cardiology 2012 [18], and recommendations of the European Food Safety Authority (EFSA) [19].

Assessment of frequency of fat consumption. Fat consumption quality was estimated with the use of the Questionnaire of Food Products Frequency Intake (FFQ). The FFQ questionnaire included 20 nutritional products treated as a main source of fats. The frequency of consumption during the previous month was estimated on the basis of 7 categories (ranges), such as: not eaten at all, eaten once a month, 2-3 times a month, once a week, 3 times a week, 4-6 times a week, eaten every day.

Statistical analysis. All analyses were carried out using the statistical package 'Statistics for Windows' (Statsoft, Poland, version 10.0). Non-parametric Mann-Whitney U test was used to ascertain statistical differences between arithmetic means of nutritional parameters in the female and male groups. Statistical significance of percentage share of the men's and women's responses for each question was analysed using $\chi 2$ test. The differences were considered to be significant for $\mathrm{p}<0.05$.

\section{RESULTS}

The mean value of Dietary Antioxidant Index (DAI), expressed as the value of total antioxidant capacity $(\mathrm{mMol} / \mathrm{l})$, measured as the ability to reduce ferric ions to ferrous ions (FRAP) of all examined persons was $34.27 \pm 11.72 \mathrm{mMol} / \mathrm{l}$. The largest percentage of studied people had FRAP values in the range $25-35 \mathrm{mMol} / \mathrm{l}$ (Fig. 1).

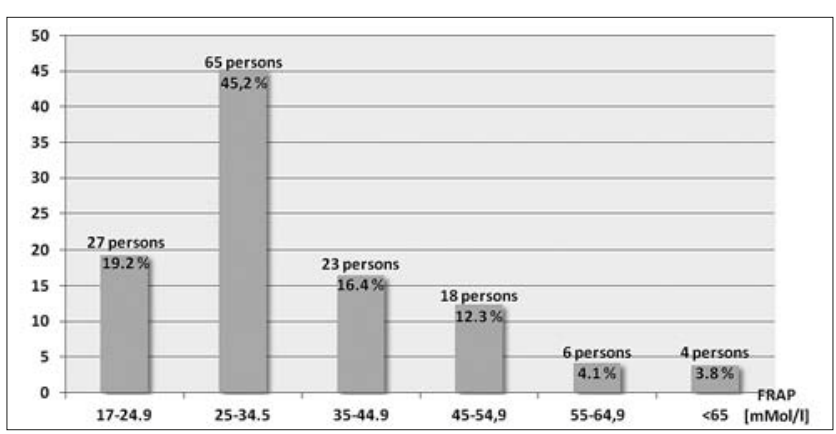

Figure 1. Frequency distributions of FRAP values obtained from studied people $(n=143)$

The mean FRAP values of particular groups of food products and their proportional contribution in DAI values in all studied people are presented in Table 1, and in female and male subgroups in Figure 2.

Both in the female and male groups, fruits had the biggest contribution in Total Dietary Antioxidant Index. They were eaten more frequently by women than men $(\mathrm{p}<0.05)$. Grains and cereal-based products were in the second position (there were no statistically significant differences in DAI values between results obtained for men and women).

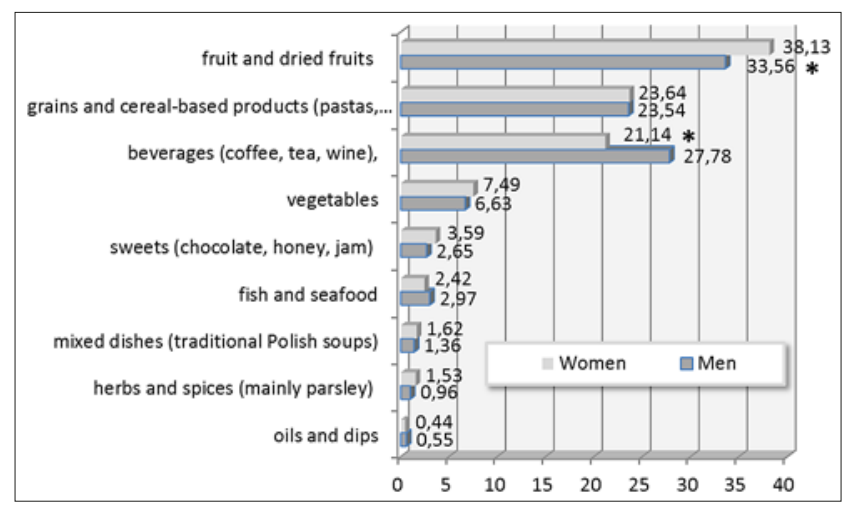

Figure 2. Percentage contribution in FRAP values ( $\mathrm{mMol} / \mathrm{l}$ ) of particular groups of food products in daily diet of all studied women $(n=73)$ and all studied men $(n=70)$ ${ }^{*} \mathrm{p}<0.05$

Table 1. Contribution of particular groups of food products in Total Dietary Antioxidant Index (DAI) in all studied people

\begin{tabular}{|c|c|c|c|c|c|c|}
\hline Groups of food products & Mean & Median & Min & Max & SD & $\% \mathrm{DAl}$ \\
\hline Fruits and dried fruits & 12.39 & 9.56 & 2.21 & 32.34 & 4.43 & 36.15 \\
\hline Vegetables & 2.44 & 2.23 & 0.47 & 6.19 & 1.22 & 7.12 \\
\hline Herbs and spices & 0.44 & 0.18 & 0 & 6.62 & 0.83 & 1.28 \\
\hline $\begin{array}{l}\text { Grains and cereal-based } \\
\text { products (pastas, rice, nuts) }\end{array}$ & 8.09 & 7.16 & 1.5 & 27.12 & 4.62 & 23.61 \\
\hline Fish and seafood & 0.91 & 0.99 & 0.28 & 2.01 & 0.34 & 2.65 \\
\hline Mixed dishes & 0.52 & 0.48 & 0 & 1.23 & 0.29 & 1.52 \\
\hline Oils and dips & 0.17 & 0.14 & 0.02 & 0.63 & 0.10 & 0.50 \\
\hline Sweets (chocolate, honey, jam) & 1.09 & 0.79 & 0.08 & 7.18 & 1,02 & 3.18 \\
\hline Beverages & 8.22 & 7.07 & 0.92 & 27.65 & 4.74 & 23.99 \\
\hline $\begin{array}{l}\text { FRAP value (mMol/l) of daily } \\
\text { nutritional ration }\end{array}$ & 34.27 & 31.39 & 17.48 & 71.66 & 11.72 & $100 \%$ \\
\hline
\end{tabular}

Beverages were consumed more frequently by men than woman $(\mathrm{p}<0.05)$. Unfortunately, in both examined groups, the vegetables were eaten too rarely (only $7.49 \%$ of women and $6.63 \%$ of men in total DAI values). The contribution of the remaining food products (fresh herbs and spices, fish and seafood, fats and oils, mixed dishes and sweets) was low.

The consumption of total fat, fatty acids and cholesterol contained in the Daily Nutritional Ration (DNR) of the studied men and women is presented in Table 2, and the percentage share of fat and particular types of fatty acids in the energetic value of DNR is presented in Table 3.

Table 2. Intake of fat, fatty acids and cholesterol in DNR by elderly people

\begin{tabular}{|c|c|c|c|c|c|}
\hline \multirow{2}{*}{ Ingredient } & \multicolumn{2}{|c|}{ Men } & \multicolumn{2}{|c|}{ Women } & \multirow{2}{*}{$\mathrm{P}$} \\
\hline & $x$ & SD & $x$ & SD & \\
\hline Total fat [g] & 70.28 & 7.86 & 70.57 & 8.61 & $\begin{array}{c}\text { Ns } \\
(0,837)\end{array}$ \\
\hline Saturated fatty acids [g] & 22.68 & 3.68 & 22.15 & 3.77 & $\begin{array}{c}\text { ns } \\
(0,417)\end{array}$ \\
\hline Monounsaturated fatty acids [g] & 20.68 & 3.27 & 20.35 & 3.26 & $\begin{array}{c}\text { ns } \\
(0,564)\end{array}$ \\
\hline Polyunsaturated fatty acids [g] & 6.02 & 1.73 & 6.05 & 1.73 & $\begin{array}{c}\text { ns } \\
(0,933)\end{array}$ \\
\hline Cholesterol [mg] & 230 & 48 & 226 & 48 & $\begin{array}{c}\text { ns } \\
(0,583)\end{array}$ \\
\hline
\end{tabular}


Table 3. Percentage participation of fats and fatty acids (saturated fatty acids - SFA; monounsaturated fatty acids - MUFA; Polyunsaturated fatty acids PUFA) in obtained energetic value of DNR of examined persons

\begin{tabular}{lcccccc}
\hline & \multicolumn{3}{c}{ Men } & \multicolumn{4}{c}{ Women } \\
\cline { 2 - 7 } Ingredient & {$[\mathrm{kcal}]$} & $\begin{array}{c}\text { Recommended } \\
\text { intake }\end{array}$ & {$[\%]$} & {$[\mathrm{kcal}]$} & $\begin{array}{c}\text { Recommended } \\
\text { intake }\end{array}$ & {$[\%]$} \\
\hline Fats & 632.52 & $<30 \%^{*},^{* * *}$ & 34.22 & 635.13 & $<30 \%^{* * * * *}$ & 34.48 \\
\hline SFA & 201.41 & $\begin{array}{c}<10 \% \%^{* *} \\
<7 \% \%^{* *}\end{array}$ & 14.0 & 199.35 & $\begin{array}{l}<10 \%^{* *} \\
<7 \% \%^{* * *}\end{array}$ & 13.83 \\
\hline MUFA & 183.45 & $<20 \%^{* * *}$ & 13.5 & 143.25 & $<20 \%^{* * *}$ & 11.0 \\
\hline PUFA & 53.36 & $6-10 \%^{* * *},,^{* * * *}$ & 3.92 & 57.21 & $6-10 \%^{* * * * * * *}$ & 4.39 \\
\hline
\end{tabular}

* Recommendations of Norms of Human Nutrition [16].

**Recommendations of Polish Forum of Prophylactic of Cardiovascular diseases [17].

***Recommendations of Healthy Diet According to Polish Cardiology 2012 [18].

****Recommendations of the European Food Safety Authority (EFSA) [19].

The fat consumption in the daily nutritional ration was similar in the male and female groups (about $70 \mathrm{~g} / 24$ hours). This value was about $34 \%$ of the energetic value of the diet, and exceeded the nutritional recommendation for elderly people. The mean consumption of saturated fatty acids was $22 \mathrm{~g} /$ day in the diet of respondents of both genders. This value was about $14 \%$ of the energetic value of the daily diet of elderly people included in the study. The level of saturated fatty acids exceeded nutritional recommendations, according to which saturated fatty acids should deliver no more than $10 \%$ of the energy included in meals, and among persons with increased cardiovascular risk, even less than $7 \%$ of energy. It was also evidenced that most women (66\%) used a diet with a bigger percentage share of saturated fatty acids. In group of men, 59\% of the participants consumed saturated fatty acids on a level lower than $10 \%$ in daily diet. The amount of monounsaturated fatty acids was $13.5 \%$ of the energetic value in men, and $11.0 \%$ of the energetic value in group of women group, which was insufficient according to the recommendation. The amount of polyunsaturated fatty acids in the diets of the analyzed group, on average, was $6 \mathrm{~g}$, which constituted $3.9 \%$ of the energy value of the diet among the men, and $4.4 \%$ of the energy value of the diet among the women. The data collected showed an insufficient consumption of polyunsaturated fatty acids versus current nutritional recommendations. Cholesterol consumption in the diets was on the level of $230 \mathrm{mg} / 24$ hours in men and $226 \mathrm{mg} / 24$ hours in the group of women. These values were in accordance with nutritional recommendations (cholesterol consumption should not exceed $300 \mathrm{mg} / 24$ hours in a wellbalanced diet).

Analysis of the Food Frequency Questionnaire allows the statement that the main sources of fats were sausages and frankfurters (consumed by $36 \%$ of men and $24 \%$ of women, with a frequency of 4-6 times a week $(p<0.05)$, and butter consumed with the same frequency by $20.5 \%$ of men and $37.2 \%$ of women $(\mathrm{p}<0.05)$. Eggs were eaten $2-3$ times a week by $40 \%$ of all examined individuals. More women (50\%) than men (20\%) consumed cakes and layer cakes 2-3 times a week $(\mathrm{p}<0.05)$, and chocolate products $(30 \%$ vs $20 \%)$ which were consumed once a week. Vegetable oils were usually consumed 2-3 times a week ( $40 \%$ men and $25 \%$ women), and semi-hard pressed rennet cheese once a week $(25 \%$ of men and $34 \%$ of women). Lard was eaten only by $22 \%$ of men once a week. The studied people reported low consumption of fish (once a month: $7.2 \%$ of men and $10 \%$ of women). $20 \%$ of men and women consumed nuts and seeds of oily plants once a month.

\section{DISCUSSION}

In primary and secondary prevention of diseases resulting from antioxidant failure and changes towards oxidation processes, the intake of exogenic antioxidants from food is very important [20]. The total antioxidant capacity (measured as DAI) of the diet among the studied elderly people (38.49 mMol/1 - women and $29.91 \mathrm{mMol} / \mathrm{l}$ - men) was lower than that obtained in a previous report by the authors of the presented study, based on 350 healthy inhabitants of Krakow aged $42.3 \pm 14.1$ years $(80.26 \mathrm{mMol} / \mathrm{l}$ - women and $46.95 \mathrm{mMol} / \mathrm{l}$ - men), and 80 students from the Jagiellonian University and Technical Academy, aged 24.2 \pm 2.4 years (92.24 mMol/l - women and $50.89 \mathrm{mMol} / \mathrm{l}$ - men) [21]. This indicates that those who were studied consumed too little antioxidant food, such as fruits, vegetables and vegetable oils, as well as grains and cereal-based products, fresh herbs and beverages. Besides the incorrect intake of antioxidants, many mistakes in the range of fat consumption were evidenced in the dietary scheme of the studied people. Similar to results obtained from another Polish population [22], in the current study there was also found an excessive consumption of SFA, together with a parallel low supply in PUFA. Therefore, in individual counseling sessions with a dietitian, the participants were encouraged to change their diet and instructed to consume more fruit, vegetables, walnuts, and other natural products with a proper content of polysaccharides and fatty acids. Literature data indicate that increased consumption of fruit and vegetables is recommended as a key component of a healthy diet for the prevention of chronic diseases [23]. A meta-analysis including 16 prospective cohort studies (data sources: MEDLINE, Embase, and the Cochrane Library) provided further evidence that a higher consumption of fruit and vegetables (around 5 servings of fruit and vegetables a day) is associated with a lower risk of all-cause mortality, particularly cardiovascular mortality [24]. An earlier examination showed that the risk of CHD may be decreased by $4 \%$ [RR (95\% CI): 0.96 (0.93-0.99); P = 0,0027] for each additional portion of fruit and vegetables per day, and by $7 \%[0.93$ (0.89-0.96); $\mathrm{P}<0,0001]$ for the portion of fruit intake [25]. The consumption of fruit and vegetables, particularly green leafy vegetables and vitamin $\mathrm{C}$-rich fruit and vegetables, appears to have a protective effect against coronary heart disease [26]. There is also growing evidence that lycopene, carotenoid without provitamin A activity, found in high concentrations in a small number of plant foods (tomato, watermelon, pink grapefruit, papaya and apricot), have significant antioxidant potential in vitro, which suggests their role in the prevention of cardiovascular disease. Additionally, lycopene may have a cholesterol synthesis-inhibiting effect that may enhance LDL degradation. It has been found that a higher lycopene concentration in plasma was associated with a lower risk of CVD in middle-aged and elderly women [27], although this effect was not confirmed in the study of older men [28]. Regular consumption of nuts has been associated with reduced risk of cardiovascular disease [28]: a walnutrich diet resulted in favorable changes in lipid levels and in weight loss [29]. Most nuts contain monounsaturated fatty acids, and walnuts are a rich source of polyunsaturated fatty acids, particularly the omega- 3 fatty acids, alfa-linolenic acid, and omega-6 linoleic acid. Walnuts also provide antioxidants (tocopherols, phenolic compounds and allagic acid [30, 31]. 
Literature data also indicate that a proper amount and quality of total fats and fatty acids from subsequent groups: SFA, MUFA and PUFA may bring many benefits in the prevention of cardiovascular system diseases. The results presented by Willett [32] indicate that specific dietary fatty acids play important roles in the cause and prevention of $\mathrm{CHD}$, but total fat as a percent of energy is not important. Also, the ratio of omega- 6 to omega- 3 is not useful. Trans-fatty acids from partially hydrogenated vegetable oils have clear adverse effects and should be eliminated from the diet. Saturated fat should be replaced by a combination of poly- and monounsaturated fat; however, the benefits of polyunsaturated fat appear to be stronger. Little or no benefit is gained if saturated fats are replaced by carbohydrates, because carbohydrates, particularly refined carbohydrates and added sugars, increase the levels of triglycerides and small LDL particles, and reduce high-density lipoprotein cholesterol [33]. Therefore, Willet [31] claims that in practice, reducing red meat and dairy products in the food supply and increasing the intake of nuts, fish, soy products, and non-hydrogenated vegetable oils, will improve the mix of fatty acids and have a markedly beneficial effect on the rates of CHD. This is the same as the recommendation given in one of the studies [34] and especially that by the American Heart Association [35]. These recommendations emphasize replacing SFAs with PUFAs in the diet, while also providing specific food-based dietary goals, including recommendations for promoting the consumption of fish, nuts, legumes, and seeds, while also limiting the intake of processed meats. The American Heart Association recommends (DALLAS, 7 February 2013) limiting saturated fats and consuming instead healthier fats, such as mono- and poly-unsaturated fats. The association bases its recommendations on a robust body of scientific studies that demonstrated a strong association between eating a diet high in saturated fat, and the development of atherosclerosis which clogs arteries and causes heart disease. Hosseinpour-Niazi et al. [36] showed that SFA intakes were positively associated with the prevalence of metabolic syndrome, independent of total dietary fat, MUFA and PUFA intake. However, total dietary fat may modulate the association between SFA and some components of metabolic syndrome results, emphasizing that both the quality and quantity of dietary fat are relevant with metabolic syndrome and cardiometabolic risk factors.

It is worth emphasizing that all authors are unanimous and that the most prudent and scientifically supportable recommendation for the general and elderly population is to consume a well-balanced diet rich in antioxidants originating from fresh fruit, vegetables and whole grains. The diet should contain proper nutritional components, especially fats and fatty acids (both in quantity and quality). This is especially important because most randomized, controlled trials have not found antioxidant supplementation to be effective for the prevention of different diseases caused by oxidative stress, including CHD [37]. The Physicians' Health Study II showed that long-term vitamin $\mathrm{E}$ or vitamin E supplementation did not reduce the risk of major cardiovascular events in middle-aged and older men [38]. In Cochrane Review of 2008 (updated in 2012 [40], it was demonstrated that antioxidant supplements (beta-carotene, vitamin A, vitamin C, vitamin E, and selenium) seem to increase mortality [39]. This study included 78 randomized trials with 296,707 participants who were either healthy (primary prevention trials), or had various diseases in a stable phase: gastrointestinal, cardiovascular, neurological, ocular, dermatological, rheumatoid, renal, endocrinological, or unspecified diseases (secondary prevention trials). The authors found no evidence to support antioxidant supplements for primary or secondary prevention. Additionally, the review showed that the potential health damage and increased risk of mortality was associated with beta-carotene, and possibly with vitamin $\mathrm{E}$ and vitamin A, but was not associated with the use of vitamin $\mathrm{C}$ or selenium. Generally, it is not recommended to use the antioxidant supplements in the general population, or in the group of patients with various diseases.

Limitation of the study. The initial intention of the authors of the presented study was to check if there is a relation between the intake of antioxidants in the daily diet, and the antioxidants level in the plasma of elderly people, as well as between the consumption of fats and plasma lipids and lipoproteins. Unfortunately, no consent was given by the people in the study for the collection of blood samples. Therefore, the study had to be restricted only to the intake of antioxidants and lipids in foods.

\section{CONCLUSIONS}

1. The majority of elderly people made nutrition mistakes, mainly in terms of fat quantity and quantity and low consumption of antioxidant-rich fruit and vegetables, and whole grains and cereal-based products.

2. In order to improve the nutrition of the studied population and to protect them against the development of cardiovascular diseases, a 10-day balanced menu, adjusted to their health condition and individual preferences, was constructed for each person in the study.

\section{Acknowledgment}

The authors wish to acknowledge the assistance rendered by Karolina Faron and Natalia Kurdziel in the collection of data.

\section{Conflict of interests}

The authors declare that they have no conflicting interests.

\section{REFERENCES}

1. Hu FB, Willett WC. Optimal diets for prevention of coronary heart disease. JAMA 2002; 288 (20):2569-2578

2. Piotrowski W, Waśkiewicz A, Cicha-Mikołajczyk A. The global risk for cardiovascular death in the adult Polish population: Prospective assessment of the cohorts studied within the Multi-center National Research on the Polish Population Health Status (WOBASZ and WOBASZ Senior)]. Kardiol Pol. 2016;76 (3)262-273.

3. Drygas W, Niklas AA, Piwońska A, Piotrowski W, Flotyńska A, Kwaśniewska $M$ et al. Multi-center National Population Health Examination Survey (WOBASZ II study): assumptions, methods and implementation. Kardiol Pol. 2015 Dec 1. doi: 10.5603/KP.a2015.0235. [Epub ahead of print].

4. Waśkiewicz A, Szcześniewska D, Szostak-Węgierek D, Kwaśniewska M, Stepaniak U, Kozakiewicz K et al. Are dietary habits of the Polish population consistent with the recommendations for prevention of cardiovascular disease? -WOBASZ II Project. Polish Heart Journal. Kardiol Pol DOI: 10.5603/KP.a2016.0003. Published online: 2016-01-07

5. Yusuf S, Hawken S, Ounpuu S, Dans T, Avezum A, Lanas F et al. Effect of potentially modifiable risk factors associated with myocardial infarction in 52 countries (the INTERHEART study): case-control study. Lancet 2004; 364(9438):937-952. 
6. Kalam S, Gul MZ, Singh R, Ankati S. Free radicals: implications in etiology of chronic diseases and their amelioration through nutraceuticals. Pharmacologia 2015; 6: 11-20.

7. Rahman K. Studies on free radicals, antioxidants and co-factors. Clin. Interv. Aging 2007; 2: 219-236.

8. Shantsila E, Wrigley B, Blann A D, Gill PS, Lip GY.H. A contemporary view on endothelial function in heart failure. Eur J Heart Fail. 2012; 14 (8): 873-881.

9. Kohlhaas M, Liu T, Knopp A, Zeller T, Ong MF, Böhm M et al. Elevated cytosolic $\mathrm{Na}+$ increases mitochondrial formation of reactive oxygen species in failing cardiac myocytes. Circulation 2010;121(14):1606-1613 doi: 10.1161/CIRCULATION AHA.109.914911. Epub 2010 Mar 29.

10. Kohlhaas M, Maack C. Calcium release microdomains and mitochondria. Cardiovasc Res 2013; 98(2):259-568. doi: 10.1093/cvr/ cvt032. Epub 2013 Feb 14.

11. Bay J, Kohlhaas M, Maack C. Intracellular Na and cardiac metabolism. J Mol Cell Cardiol 2013; 61:20-27. doi: 10.1016/j.yjmcc.2013.05.010. Epub 2013 May 28.

12. Zhang H, Gomez AM, Wang X, Yan Y, Zheng M, Cheng H. ROS regulation of microdomain $\mathrm{Ca}(2+)$ signalling at the dyads. Cardiovasc Res 2013;98(2):248-58. doi: 10.1093/cvr/cvt050. Epub 2013 Mar 1.

13. Satia JA, Watters JL, Galanko JA. Validation of an Antioxidant Nutrient Questionnaire in Whites and African Americans. J Am Diet Assoc. 2009; 109:502-508.

14. Benzie IF, Strain JJ. The ferric reducing ability of plasma (FRAP) as a measure of "antioxidant power": the FRAP assay. Anal Biochem. 1996; 239: 70-76.

15. Szponar L, Wolnicka K, Rychlik E. Album of food products and dishes. National Food and Nutrition Institute, Warszawa, 2000.

16. Jarosz M. Polish nutritional guidelines - amendment. National Food and Nutrition Institute. Warszawa, 2012.

17. Kłosiewicz-Latoszek L, Szostak WB, Podolec P. Nutrition Guidelines of Polish Forum of Circulation System Disease Prophylaxis. In: www. pfp.edu.pl (accessed on April 30th, 2014).

18. European guidelines in prophylaxis of cardiovascular diseases in clinical practice. Kardiol Pol. 2012; 70: 39-43.

19. European Ford Safety Authority (EFSA). Scientific opinion on dietary reference values for fats including saturated fatty acids, polyunsaturated fatty acids, monounsaturated fatty acids and cholesterol. EFSA Journal 2010; 8:1461.

20. Butnariu M, Caunii A: Design management of functional foods for quality of life improvement. Ann Agric Environ Med. 2013, 20: 736-741.

21. Kolarzyk E, Pietrzycka A, Kaczyńska-Ratka A, Skop-Lewandowska A. Diet with high antioxidant capacity as important factor in primary and secondary prevention of asthma. Przegl Lek. 2015;72 (12): 743-746 (in Polish).

22. Zatonska K, Campos H, Ilow R, Janik-Koncewicz K, Różanska D, Regulska-Ilow B et al. Dietary intake and adipose tissue level of specific fatty acids in a selected group from the Lower Silesia population. Ann Agric Environ Med. 2012; 19(3): 389-394.

23. Joint WHO/FAO Expert Consultation. Diet, nutrition and the prevention of chronic diseases. World Health Organ Tech Rep Ser. 2003;916:1-149.

24. Wang X, Ouyang Y, Liu J, Zhu M, Zhao G, Bao W et al. Fruit and vegetable consumption and mortality from all causes, cardiovascular disease, and cancer: systematic review and dose-response meta-analysis of prospective cohort studies. BMJ 2014;349:g4490.

25. Dauchet L, Philippe, Amouyel P, Hercberg S, Dallongeville J. Fruit and vegetable consumption and risk of coronary heart disease: a metaanalysis of cohort studies. Ann Intern Med. 2001;134:1106-1114.
26. Joshipura K J, Hu F B, Manson J E, Stampfer MJ, Rimm EB, Speizer FE et al. The effect of fruit and vegetable intake on risk for coronary heart disease. J Nutr. 2006; 136, 2588-2593.

27. Sesso HD, Buring JE, Norkus EP, Gaziano JM. Plasma lycopene, other carotenoids, and retinol and the risk of cardiovascular disease in women. Am J Clin Nutr. 2004;79(1):47-53.

28. Sesso HD, Buring JE, Norkus EP, Gaziano JM. Plasma lycopene, other carotenoids, and retinol and the risk of cardiovascular disease in men. Am J Clin Nutr. 2005;81(5):990-997.

29. Feldman EB. The scientific evidence for a beneficial health relationship between walnuts and coronary heart disease. J Nutr. 2002;132(5):10621101.

30. Le T, Flatt SW, Natarajan L, Pakiz B, Quintana EL, Heath DD et al. Effects of diet composition and insulin resistance status on plasma lipid levels in a weight loss intervention in women. J Am Heart Assoc. 2016;5(1). pii: e002771. doi: 10.1161/JAHA.115.002771.

31. Kris-Etherton PM. Walnuts decrease risk of cardiovascular disease: a summary of efficacy and biologic mechanisms. J Nutr. 2014;144(4 Suppl):547S-554S. doi: 10.3945/jn.113.182907. Epub 2014 Feb 5.

32. Willett WC. Dietary fats and coronary heart disease. J Intern Med. 2012;272(1):13-24. doi: 10.1111/j.1365-2796.2012.02553.x.

33. Siri-Tarino PW, Sun Q, Hu FB, Krauss RM. Saturated fatty acids and risk of coronary heart disease: modulation by replacement nutrients. Curr Atheroscler Rep. 2010;12b(6):384-390. doi: 10.1007/s11883-0100131-6.

34. Virtanen JK, Mursu J, Tuomainen T-P, Voutilainen S. Dietary fatty acids and risk of coronary heart disease in men: the Kuopio ischemic heart disease risk factor study. Arterioscler Thromb Vasc Biol. 2014;34:26792687.

35. Lloyd-Jones DM, Hong Y, Labarthe D et al. American Heart Association Strategic Planning Task Force and Statistics Committee. Defining and setting national goals for cardiovascular health promotion and disease reduction: the American Heart Association's strategic Impact Goal through 2020 and beyond. Circulation 2010;121:586-613.

36. Hosseinpour-Niazi S, Mirmiran P, Fallah A, Azizi F. Combined effect of unsaturated fatty acids and saturated fatty acids on the metabolic syndrome: Tehran Lipid and Glucose Sstudy. J Health Popul Nutr. 2015; 33:5 DOI: 10.1186/s41043-015-0015

37. Seung-Kwon M, Woong J, Belong Ch, Seung-Won O, Sang Min P, Bon-Kwon $\mathrm{K}$ et al. Efficacy of vitamin and antioxidant supplements in prevention of cardiovascular disease: systematic review and meta-analysis of randomised controlled trials. BMJ 2013; 346 doi: http://dx.doi.org/10.1136/bmj.f10 (Published 18 January 2013). BMJ 2013;346:f10

38. Sesso HD, Buring JE, Christen WG, Kurth T, Belanger C, MacFadyen J, et al. Vitamins $\mathrm{E}$ and $\mathrm{C}$ in the prevention of cardiovascular disease in men: the Physicians' Health Study II randomized controlled trial. JAMA. 2008 Nov 12;300(18):2123-33. doi: 10.1001/jama.2008.600. Epub 2008 Nov 9.

39. Bjelakovic G, Nikolova D, Gluud LL, Simonetti RG, Gluud C. Antioxidant supplements for prevention of mortality in healthy participants and patients with various diseases. Cochrane Database of Systematic Reviews. 2008, Issue 2. Art. No.: CD007176. DOI: 10.1002/14651858.CD007176.

40. Bjelakovic G, Nikolova D, Gluud LL, Simonetti RG, Gluud C. Antioxidant supplements for prevention of mortality in healthy participants and patients with various diseases. Cochrane Database of Systematic Reviews. 2012, Issue 3. Art. No.: CD007176. DOI: 10.1002/14651858.CD007176.pub2. 